\title{
Editorial: Environmental Bioenergetics
}

\author{
Anke M. Herrmann ${ }^{1 *}$, Douglas E. LaRowe ${ }^{2}$ and Alain F. Plante ${ }^{3}$ \\ ${ }^{1}$ Department of Soil and Environment, Swedish University of Agricultural Sciences, Uppsala, Sweden, ${ }^{2}$ Department of Earth \\ Sciences, University of Southern California, Los Angeles, CA, United States, ${ }^{3}$ Department of Earth and Environmental \\ Science, University of Pennsylvania, Philadelphia, PA, United States
}

Keywords: energy, thermodynamics, calorimetry, energy-limited environments, soil, sediment

\section{Editorial on the Research Topic}

\section{Environmental Bioenergetics}

Energy is continuously transformed in the environment through the metabolic activities of organisms. Catabolic reactions generate energy (energy-yielding) which are used to fuel anabolic reactions for maintenance and growth (energy-requiring). These transformations of energy (i.e., bioenergetics) underpin most biogeochemical cycles on Earth and allow the delivery of a wide range of life-supporting ecosystem services. It has long been understood that the amount and types of energy available in an environment influence the rates of biological activity and the complexity of interactions in that system. Traditionally, energy fluxes and stocks have not been described in a quantitative manner, and it is not well-understood how physicochemical theorems such as thermodynamic principles are manifested in environmental systems. Theoretical ecological

OPEN ACCESS

Edited and reviewed by: Bradley M. Tebo,

Oregon Health \& Science University, United States

*Correspondence:

Anke M. Herrmann anke.herrmann@slu.se

Specialty section:

This article was submitted to

Microbiological Chemistry and

Geomicrobiology,

a section of the journal

Frontiers in Environmental Science

Received: 25 July 2019

Accepted: 27 August 2019

Published: 10 September 2019

Citation:

Herrmann AM, LaRowe DE and Plante AF (2019) Editorial:

Environmental Bioenergetics.

Front. Environ. Sci. 7:132. doi: 10.3389/fenvs.2019.00132 frameworks (Odum, 1969; Addiscott, 1995) have suggested that the more complex ecosystems become in terms of their food webs, the more efficient they are, i.e., relatively less energy is wasted when utilizing resources. However, this has not been rigorously tested experimentally, but in recent years, scientists in a number of fields have increasingly shown interest in quantifying how bioenergetics constrain and define ecosystem functioning. For example, organic matter in soils has distinct energetic signatures, e.g., energy densities and activation energies (Barré et al., 2016; Williams et al., 2018), and microbial bioenergetics provides empirical data for mechanistic models of carbon turnover in soils, work that is relevant to climate change (Sparling, 1983; Herrmann et al., 2014; Barros et al., 2016; Bölscher et al., 2017). Furthermore, geochemists have quantified the amount of chemolithotrophic energy available for microorganisms in a number of extreme environments to infer the dominant metabolic activities (e.g., McCollom and Shock, 1997; Shock et al., 2010; Osburn et al., 2014). These activities are challenging to monitor due to their inaccessibility and incredibly slow rates of energy processing. Although all of these efforts represent significant progress in the field of biogeochemistry, bioenergetics analysis of natural systems is still in its infancy. Nonetheless, there is increasing interest in using bioenergetics tools to better characterize biogeochemical cycling in water, soils, and sediments in terrestrial, freshwater, and marine ecosystems.

In this general context, this Research Topic aims to gather contributions from scientists working in diverse disciplines who have a common interest in evaluating bioenergetics at various spatio-temporal scales in a variety of different environments. The scientific disciplines involved include microbial chemistry, geomicrobiology, extreme microbiology, and soil biogeochemistry, and these articles show the diversity of topics demonstrating the environmental breadth of bioenergetics. 


\section{MICROBIAL CHEMISTRY}

In two companion papers, Jin and Kirk and Jin and Kirk explore how $\mathrm{pH}$ affects the thermodynamics and kinetics of microbial respiration using geochemical reaction modeling. Their approach is an expansion of the work proposed by Bethke et al. (2011), and by using such a reductionist approach, they show that $\mathrm{pH}$ is an important factor in shaping the composition and functioning of microbial communities. In another reductionist approach, Harris et al. examine the capability of nine Shewanella strains to transport extracellular electrons to insoluble electron acceptors such as metal oxides. Five strains are capable of this behavior with some strains showing a preference for a particular metal oxide. Such fundamental studies provide information on underlying basic processes occurring in complex interactions in the environment.

\section{GEOMICROBIOLOGY}

Interactions between microorganisms and minerals play an important role in the transformation of rocks in natural systems (Banfield and Nealson, 1997; Shock, 2009). In this Research Topic, Dhami et al. explore the intersection of microbial ecology, geochemistry and the mechanical properties of minerals, and conclude that physicochemical conditions are important in selecting microbial communities under different environmental conditions. Liu et al. address how biologically produced minerals exert influence over the transport of metal ions and thus how microbial behavior modifies ecosystems. Finally, in a modeling article, Vallino and Huber put forward a complementary holistic approach based on thermodynamics. They evaluate the principle of maximum entropy production by combining a metabolic network, a transport model and an entropy production and optimization procedure. In this approach, field observations and modeling are combined and the results support their hypothesis that biological systems evolve and organize to maximize entropy production over a wide range of spatio-temporal scales.

\section{EXTREME MICROBIOLOGY}

Marine (sediment, oceanic basement, seep habitats) and continental (crust, ores, and aquifers) environments are energylimited habitats. Haas et al. explore the biogeochemistry of anoxygenic photosynthesis in a thick microbial mat in Magical Blue Hole in The Bahamas. When iron is present, sulfur cycling slows down considerably. Yet, despite extreme light limitations, green sulfur bacteria were able to carry out anoxygenic photosynthesis, producing a potential biomarker for extreme low-light environments. In a review paper, Bradley et al. summarize diagenetic models (Arndt et al., 2013) commonly used to evaluate microbial energetics in marine sediments (e.g., growth rate, yield maintenance, and the physiological state of microorganisms), and provide a new model where all factors including dormancy are encompassed. Such a modeling tool will advance our understanding of why microbial communities can persist under unfavorable conditions on geological timescales. Marine sediments therefore can serve as a model system for how life could persist on extra-terrestrial settings. In a review paper, Jones et al. present an overview of how energetic limitation in subsurface environments can serve as potential analogs for life on other planetary bodies. The value of these contributions go beyond our understanding of processes on planet Earth.

\section{SOIL BIOGEOCHEMISTRY}

Soil organic matter serves as carbon and energy source for microorganisms, and the use of the average nominal oxidation state of carbon has been suggested as a universal metric of the bioenergetics potential of microbial metabolism decomposing organic matter in soils (LaRowe and Van Cappellen, 2011; Nunan et al., 2015; Gunina et al., 2017). In the current Research Topic, Boye et al. extend this approach to make progress on sustainable land-use management issues such as the degradation of organic matter in oxygen-limited rice paddy systems. Using energy balances of redox-processes, their results indicate that watersoluble carbon is key driver of microbial processes with major impacts on ecosystem functioning. Arcand et al. explore the functional importance of soil biota, including their composition, in organic and conventional management systems. Combining isothermal calorimetry with ${ }^{13} \mathrm{C}$-DNA stable isotope probing, they demonstrate that long-term agricultural management can alter microbially driven carbon processes in soils. Furthermore, Williams and Plante propose a bioenergetics framework for assessing the persistence of organic matter in soil systems. The framework is based on a return-on-investment ratio, the ratio between energy invested in relation to energy density (Harvey et al., 2016). Their framework contradicts traditional humus theory that organic matter is composed of inherently stable macromolecules; instead it supports the idea that organic matter is a continuum of progressively decomposing organic compounds (Lehmann and Kleber, 2015).

\section{CONCLUSIONS}

The 12 articles comprising this Research Topic only begin to scratch the surface of the very broad emerging research area of environmental bioenergetics. By taking an energetic view of microbial metabolism in various environments, we may (i) further our understanding of the link between microbial communities and their activities in relation to geochemical processes, and (ii) improve our prediction of microbial feedback mechanisms and ecosystem responses to climate change. The publication of this volume comes at a key moment in which the delivery of ecosystem services is of high importance (IPBES, 2019) and the need to achieve the UN Sustainable Development Goals for 2030 (UN-DSDG, 2019) becomes an increasingly urgent issue. We aspire that this collective work will inform and stimulate more studies on this Research Topic in the coming years, and we advocate that environmental bioenergetics research (including development of new concepts and frameworks) needs to be integrated with targeted scientific research to address the pressing challenges humankind is currently faced with. 


\section{AUTHOR CONTRIBUTIONS}

All authors listed have made a substantial, direct and intellectual contribution to the work, and approved it for publication.

\section{REFERENCES}

Addiscott, T. M. (1995). Entropy and sustainability. Eur. J. Soil Sci. 46, 161-168. doi: 10.1111/j.1365-2389.1995.tb01823.x

Arndt, S., Jørgensen, B. B., LaRowe, D. E., Middelburg, J., Pancost, R., and Regnier, P. (2013). Quantifying the degradation of organic matter in marine sediments: a review and synthesis. Earth Sci. Rev. 123, 53-86. doi: 10.1016/j.earscirev.2013.02.008

Banfield, J. F., and Nealson, K. H. (1997). Geomicrobiology: Interactions Between Microbes and Minerals. Washington, DC: Mineralogical Society of America. doi: 10.1515/9781501509247

Barré, P., Plante, A. F., Cecillon, L., Lutfalla, S., Baudin, F., Bernard, S., et al. (2016). The energetic and chemical signatures of persistent soil organic matter. Biogeochemistry 130, 1-12. doi: 10.1007/s10533-016-0246-0

Barros, N., Hansen, L. D., Piñeiro, V., Pérez-Cruzado, C., Villanueva, M., Proupín, J., et al. (2016). Factors influencing the calorespirometric ratios of soil microbial metabolism. Soil Biol. Biochem. 92, 221-229. doi: 10.1016/j.soilbio.2015.10.007

Bethke, C. M., Sanford, R. A., Kirk, M. F., Jin, Q., and Flynn, T. M. (2011). The thermodynamic ladder in geomicrobiology. Am. J. Sci. 311, 183-210. doi: 10.2475/03.2011.01

Bölscher, T., Paterson, E., Freitag, T., Thornton, B., and Herrmann, A. M. (2017). Temperature sensitivity of substrate-use efficiency can result from altered microbial physiology without change to community composition. Biol. Biochem. 109, 59-69. doi: 10.1016/j.soilbio.2017.02.005

Gunina, A., Smith, A. R., Kuzyakov, Y., and Jones, D. L. (2017). Microbial uptake and utilization of low molecular weight organic substrates in soil depend on carbon oxidation state. Biogeochemistry 133, 89-100. doi: 10.1007/s10533-017-0313-1

Harvey, O. R., Myers-Pigg, A. N., Kuo, L. J., Singh, B. P., Kuehn, K. A., and Louchouarn, P. (2016). Discrimination in degradability of soil pyrogenic organic matter follows a return-on-energy-investment principle. Environ. Sci. Technol. 50, 8578-8585. doi: 10.1021/acs.est.6b01010

Herrmann, A. M., Coucheney, E., and Nunan, N. (2014). Isothermal Microcalorimetry provides new insight into terrestrial carbon cycling. Environ. Sci. Technol. 48, 4344-4352. doi: 10.1021/es403941h

IPBES (2019). Global Assessment Report on Biodiversity and Ecosystem Services. Available online at: https://www.ipbes.net/global-assessment-reportbiodiversity-ecosystem-services

LaRowe, D. E., and Van Cappellen, P. (2011). Degradation of natural organic matter: a thermodynamic analysis. Geochim. Cosmochim. Acta 75, 2030-2042. doi: 10.1016/j.gca.2011.01.020

\section{ACKNOWLEDGMENTS}

The editors want to express their profound gratitude to all authors and reviewers for their valuable contributions, which helped to achieve high standards for the contributed papers.

Lehmann, J., and Kleber, M. (2015). The contentious nature of soil organic matter. Nature 528, 60-68. doi: 10.1038/nature16069

McCollom, T. M., and Shock, E. L. (1997). Geochemical constraints on chemolithoautotrophic metabolism by microorganisms in seafloor hydrothermal systems. Geochim. Cosmochim. Acta 61, 4375-4391. doi: 10.1016/S0016-7037(97)00241-X

Nunan, N., Lerch, T. Z., Pouteau, V., Mora, P., Changey, F., Kätterer, T., et al. (2015). Metabolising old soil carbon: Simply a matter of simple organic matter? Soil Biol. Biochem. 88, 128-136. doi: 10.1016/j.soilbio.2015.05.018

Odum, E. P. (1969). The strategy of ecosystem development. Science 164, 262-270. doi: 10.1126/science.164.3877.262

Osburn, M. R., LaRowe, D. E., Momper, L., and Amend, J. P. (2014) Chemolithotrophy in the continental deep subsurface: Sanford Underground Research Facility (SURF), USA. Front. Microbiol. 5:610. doi: $10.3389 /$ fmicb.2014.00610

Shock, E. L. (2009). Minerals as energy sources for microorganisms. Econ. Geol. 104, 1235-1248. doi: 10.2113/gsecongeo.104.8.1235

Shock, E. L., Holland, M., Meyer-Dombard, D., Amend, J. P., Osburn, G. R., and Fischer, T. P. (2010). Quantifying inorganic sources of geochemical energy in hydrothermal ecosystems, Yellowstone National Park, USA. Geochim. Cosmochim. Acta 74, 4005-4043. doi: 10.1016/j.gca.2009.08.036

Sparling, G. P. (1983). Estimation of microbial biomass and activity in soil using micro-calorimetry. J. Soil Sci. 34, 381-390. doi: 10.1111/j.1365-2389.1983.tb01043.x

UN-DSDG (2019). United Nations Sustainable Development Goals. Available online at: https://sustainabledevelopment.un.org/

Williams, E. K., Fogel, M. L., Berhe, A. A., and Plante, A. F. (2018). Distinct bioenergetic signatures in particulate versus mineral-associated soil organic matter. Geoderma 330, 107-116. doi: 10.1016/j.geoderma.2018.05.024

Conflict of Interest Statement: The authors declare that the research was conducted in the absence of any commercial or financial relationships that could be construed as a potential conflict of interest.

Copyright (c) 2019 Herrmann, LaRowe and Plante. This is an open-access article distributed under the terms of the Creative Commons Attribution License (CC BY). The use, distribution or reproduction in other forums is permitted, provided the original author(s) and the copyright owner(s) are credited and that the original publication in this journal is cited, in accordance with accepted academic practice. No use, distribution or reproduction is permitted which does not comply with these terms. 